Bond University

Research Repository

\title{
Childhood sexual abuse and substance abuse in relation to depression and coping
}

Lee, S.; Lyvers, Michael; Edwards, M. S.

Published in:

Journal of Substance Use

DOI:

$10.1080 / 14659890802211077$

Licence:

Other

Link to output in Bond University research repository.

Recommended citation(APA):

Lee, S., Lyvers, M., \& Edwards, M. S. (2008). Childhood sexual abuse and substance abuse in relation to depression and coping. Journal of Substance Use, 13(5), 349-360. https://doi.org/10.1080/14659890802211077

\footnotetext{
General rights

Copyright and moral rights for the publications made accessible in the public portal are retained by the authors and/or other copyright owners and it is a condition of accessing publications that users recognise and abide by the legal requirements associated with these rights.
}

For more information, or if you believe that this document breaches copyright, please contact the Bond University research repository coordinator. 


\section{Bond University}

\section{ePublications@bond}

$10-1-2008$

\section{Childhood sexual abuse and substance abuse in relation to depression and coping}

Sonja Lee

Michael Lyvers

Bond University, michael_lyvers@bond.edu.au

Mark Edwards

Bond University, Mark_Edwards@bond.edu.au

Follow this and additional works at: http://epublications.bond.edu.au/hss_pubs

Part of the Psychology Commons

\section{Recommended Citation}

Sonja Lee, Michael Lyvers, and Mark Edwards. (2008) "Childhood sexual abuse and substance abuse in relation to depression and coping" Journal of Substance Use, 13 (5), 349-360.

http://epublications.bond.edu.au/hss_pubs/254 
Childhood Sexual Abuse and Substance Abuse: Relation to Depression and Coping Sonja Lee, MPsych (Clinical)

Michael Lyvers, Ph.D.

Mark S. Edwards, Ph.D.

Department of Psychology, Bond University

Gold Coast Qld 4229 Australia

Address correspondence to Michael Lyvers 
Abstract

Relationships between Childhood Sexual Abuse (CSA), substance abuse, substance abuse relapse, depression and coping styles were examined in an Australian sample. Participants were 79 adults actively seeking treatment for substance abuse or CSA. CSA and substance use history were assessed using a purpose built questionnaire. Depression was assessed using the Beck Depression Inventory Second Edition (BDI-II), and coping styles were evaluated using the Coping Scale for Adults. Among substance abusers, self-reported CSA history was associated with (1) severe depression; (2) less optimistic coping; (3) longer duration of substance abuse; and (4) the use of drugs to alleviate negative moods. A non-substanceabusing CSA group was remarkably similar to the CSA substance-abusing group on all measures. Penetrative abuse, younger age at CSA onset, and lack of confidence in dealing with CSA were associated with more severe depression in CSA victims. Implications for therapy and suggestions for future research are discussed.

KEYWORDS: substance disorders, childhood sexual abuse, depression, addictions, alcoholism 
Childhood Sexual Abuse and Substance Abuse in Relation to Depression and Coping Adult survivors of childhood sexual abuse (CSA) are reportedly more prone than nonvictims to psychological problems such as depression, suicide attempts, and substance disorders (Brown \& Anderson, 1991; Clay, Olsheski \& Clay, 2000; Dhaliwal et al., 1996; Finkelhor, 1986; Glasser \& Frosh, 1993; Neumann, Houskamp, Pollock \& Briere, 1996; Spak, Spak \& Allebeck, 1998; Wilsnack, Vogeltanz, Klassen \& Harris, 1997). Van Hasselt and Hersen (2000) define CSA as "any sexual act perpetrated on a child by someone sufficiently older to exercise, by nature of that age discrepancy, power over the child, or who exercises power by more direct coercion” (p.68). CSA history is said to be a contributing factor in the etiology and maintenance of addictive behavior in substance abusers (Rohsenow, Corbett \& Devine, 1988), because individuals who self-report a history of CSA are more likely to abuse substances such as alcohol and illicit drugs than those who do not (Epstein, Saunders, Kilpatrick \& Resnick, 1998; Miller, Downs, Gondoli \& Keil, 1987).

Substance abuse by adult CSA victims has been interpreted as a maladaptive coping mechanism for managing negative self-directed feelings resulting from their trauma (HiebertMurphy \& Woytkiw, 2000; Ireland \& Widom, 1994; Roesler \& Dafler, 1993). Substance abuse may provide a means to block out psychological pain by allowing the victim to dissociate from their traumatic memories (Evans, 1987; Jarvis, Copeland \& Walton, 1998; Miller \& Downs, 1996; Scher \& Twaite, 1999), or to help them manage trauma-related emotions (Greer \& Walls, 1997). In some studies, more severe forms of CSA have been shown to be associated with substance disorders in adulthood (Clay et al., 2000; Miller \& Downs, 1996), although contradictory findings have also been reported (Spak et al., 1998). Kendler, Bulik, Silberg and Hettema (2000) suggest that CSA severity is related to the likelihood of later problems including substance and depressive disorders. The age of the CSA victim is also suggested to be a factor, as some research suggests that the younger the 
victim was at the occurrence of CSA, the more likely they are to later develop a substance abuse problem or other disorders (Burnam et al., 1988; Spak et al., 1998). By contrast, other research has indicated that younger victims may be less likely than older victims to develop substance abuse or other disorders (Clay et al., 2000; Jarvis et al., 1998).

Victim gender may also influence outcome (Rice et al., 2001), with some research suggesting that a large proportion of women in substance abuse treatment programs were victims of CSA (Marcenko, Kemp \& Larson, 2000; Swift, Copeland \& Hall, 1996). For example, in a study of childhood adversity in drug and alcohol dependent women, Berry and Sellman (2001) reported that 51\% of participants disclosed severe forms of CSA (including oral, anal or vaginal sexual penetration). On the other hand, there are data to suggest that males with a history of CSA are no more likely to be in treatment for substance use disorders than are those without CSA histories (Brown \& Anderson, 1991; Rohsenow et al., 1988). CSA females are reported to have higher rates of alcoholism than CSA males (Silverman, Reinherz, \& Giaconia, 1996). Widom, Ireland and Glynn (1995) found no significant relationship between childhood abuse or neglect and later onset of alcohol problems in males, whereas a significant relationship was indicated in females. Physical and/or sexual abuse histories may thus increase the risk of later substance abuse in women more than men (Langeland \& Hartgers, 1998). However, male CSA victims have been reported to encounter more difficulties in dealing with their past victimization than CSA females (Dhaliwal et al., 1996).

Although a few researchers have suggested that stimulants such as cocaine or amphetamines are often abused by CSA substance abusers (Jarvis et al., 1998; Kalichman, Williams, Cherry, Belcher \& Nachimson, 1998), use of depressant drugs such as alcohol, sedatives, or opiates has been more often reported in CSA victims (Harrison, Hoffman \& Edwall, 1989; Heffernan et al., 2000). CSA victims may tend to use depressant drugs such as 
alcohol or opiates in an attempt to block, suppress or manage unpleasant traumatic emotions or memories (Downs et al., 1991; Schaefer et al., 1988). Some authors also claim that CSA history influences treatment outcomes and relapse rates in those who report substance disorders (Evans, 1987; Rohsenow et al., 1988; Schaefer, Sobieraj \& Hollyfield, 1988). Failure to identify underlying CSA in clients undergoing treatment for a substance disorder might therefore lead to relapse as a maladaptive coping mechanism (Bass \& Davis, 1988). Concurrent treatment of both CSA and substance abuse has been shown to reduce relapse rates in some cases (Chiavaroli, 1992). Alcoholics without a history of CSA or physical or emotional abuse tend to exhibit higher levels of general overall functioning and have better treatment outcomes than alcoholics with a CSA history (Rice et al., 2001). However Jarvis et al. found that although CSA increases the risk of early substance abuse, CSA was not related to the severity of the substance disorder, choice of substance, or relapse rates.

As indicated above, factors that may influence mental health outcomes of CSA include CSA severity, the age at CSA onset, victim gender, and coping style (Neumann, Housekamp, Pollock \& Briere, 1996). In the present study, adult male and female volunteers were recruited from both sexual abuse and substance abuse services, forming three groups for comparison: CSA substance abusers, non-CSA substance abusers, and non-substanceabusing CSA victims. The study sought to examine a number of issues. First, in substance abusers, is CSA associated with unique, clinically relevant characteristics that distinguish victims from substance abusers without such a history? For example, are substance abusers with self-reported CSA histories different in terms of level of depression, coping styles, motives for drug use, and number of treatment attempts or relapses than substance abusers without such histories, as some have hypothesized (e.g., Chiavaroli, 1992; Downs et al., 1991; Epstein et al., 1998; Jarvis et al., 1998; Rohsenow et al., 1988)? Second, in adult CSA victims, are aspects of CSA such as age at abuse onset, CSA severity, and relationship to 
perpetrator related to later outcomes such as depression and substance abuse, as has been suggested (e.g., Cheasty et al., 1998; Glaser \& Frosch, 1993; Hettema, 2000; Spak et al., 1998)? Are there gender variations in responses to CSA (Dhaliwal et al., 1996)?

On the basis of previous research, a number of findings were anticipated. Among substance abusers, CSA history was expected to be associated with worse depression, a greater number of treatment attempts/relapses, and poorer coping. Among CSA victims, penetrative CSA was predicted to be associated with worse depression compared to nonpenetrative CSA, and a younger age at CSA onset (operationally defined here as 8 years or younger) was predicted to be associated with worse depression compared to CSA victims who reported a CSA onset at age 9 or older.

Method

\section{Participants}

There were 79 participants who reported histories of CSA, substance abuse, or both. All were actively seeking treatment for their CSA and/or their substance disorder at the time of the study. Participants were recruited as volunteers without incentives from two sexual abuse services in Queensland, Australia (57\%) and from two substance abuse treatment programs in South Australia (43\%). For purposes of the present study, participants formed three groups: CSA substance abusers $(n=29)$, non-CSA substance abusers $(n=30)$, and nonsubstance abusing CSA victims $(n=20)$. There were 30 males, 48 females, and 1 whose gender was undefined. The three groups did not differ in gender composition according to chi-square test. Ages ranged from 18 to 56 years $(M=31.33$ years, $S D=8.21)$. Groups did not differ in age according to analysis of variance (ANOVA).

Of the 79 participants, 50 (63\%) indicated that they were survivors of CSA. Those who disclosed CSA histories included 16 males, 33 females and 1 undefined. Approximately half (26) of those reporting histories of CSA were abused at the age of 8 years or younger; 42 
(84\%) indicated that they had been abused more than once; and 30 (60\%) indicated that their perpetrator was either a family member or step family member. Of the CSA perpetrators, 42 (84\%) were male, 7 (14\%) were female, and 1 (2\%) respondent indicated that both male and female perpetrators had sexually abused them. Of those reporting a history of CSA, 41 (82\%) indicated that they were abused by one perpetrator, 4 (8\%) by two perpetrators, and $5(10 \%)$ indicated that they were subjected to CSA by three or more perpetrators.

Of those who reported a CSA history, 35 (70\%) indicated that their abuse was severe (i.e., it involved vaginal, anal and/or oral penetration). The remainder reported moderate CSA that involved unwanted fondling and touching. Of the participants who disclosed CSA, 30 (60\%) indicated that they did not report their abuse to anyone. Only $5(10 \%)$ of the CSA victims said their perpetrators had been charged. Of the CSA respondents, 47 (94\%) indicated that they did not feel supported by family and friends, and 37 (74\%) indicated that they did not feel confident they had dealt with their CSA.

Of the 58 participants who met the stated criteria for substance abuse, all (100\%) reported that they had tried to stop on at least one occasion; 50 (86\%) reported that they felt guilty about their substance use and that their substance use had stopped them from fulfilling role obligations at work, school or home; 34 (59\%) indicated that they had experienced legal problems because of their substance use; and 27 (47\%) indicated that they argued with significant others on a daily basis because of their substance problem. In evaluating depressive symptomatology, 52 (66\%) of the entire participant sample met the criteria for moderate to severe depression according to the criteria set for the BDI-II.

\section{Materials}

Child Sexual Abuse and Substance Abuse Questionnaire. The Child Sexual Abuse and Substance Abuse Questionnaire was developed to assess CSA history and substance abuse as well as basic demographic information. Questions pertaining to sexual abuse were written as 
sensitively as possible in an effort to gain honest, reliable information. Questions were asked about the age(s) when the abuse occurred, frequency of abuse occurrence, the relationship between themselves and the perpetrator, and the number and gender(s) of the perpetrator(s). Participants were asked to indicate the nature of their abuse, specifying either penetration (severe CSA), fondling or touching (moderate CSA), or the perpetrator engaging in exposing themselves and/or sexual talking or insinuation (i.e., no genital contact; mild CSA). Participants were then asked to indicate if their abuse was reported, if the perpetrator was charged, and whether they received support following their abuse disclosure. Finally, participants reported whether they felt confident that they had dealt with their trauma. As suggested by Miller and Downs (1996), questions were specific to sexual abuse in contrast to general victimization. Reasonably good cooperation was expected due to the anonymity of all respondents (Kendler et al., 2000). Participants were considered to be adult survivors of CSA only if they were 16 years of age or younger at the time of first sexual abuse victimization.

Participants were also asked to indicate their frequency of use of various substances from a reference list indicating daily, weekly, once monthly and never, and how long they had used each of the particular substances of choice. Further questions were asked based upon the DSM-IV diagnostic criteria pertaining to substance abuse. Single response answers (yes/no) were required to questions asking if their substance use had caused problems in fulfilling role obligations, legal problems, feelings of guilt, and adverse effects on relationships with others. For the purposes of the present study, participants were strictly defined as substance abusers only if they reported daily use of an illicit substance or alcohol and responded 'yes' to two or more of the DSM-IV criteria A for substance abuse (American Psychiatric Association, 1994, p. 182). Participants were further asked if they had ever attempted to stop their substance use, and if so, how many times. They were also asked the number of times they have sought treatment for substance use. Finally, participants were asked to identify the circumstances or 
situations where/when they were most likely to use drugs or alcohol in an attempt to identify motives for substance use. Responses were classified into two general categories, (1) relief of negative states (e.g., depression, stress, block things out), or (2) social/recreational motives (e.g., to get high, party with friends).

Beck Depression Inventory - Second Edition (BDI-II; Beck, Steer, \& Brown, 1996). The BDI-II is a 21-item self-report measure designed to assess the severity of depression in individuals aged over 13 years. Each item has several possible responses on a four-point scale, and items are in alignment with the DSM-IV criteria for depression. Participants are asked to complete the questionnaire while considering their experiences in the preceding two weeks. Aggregate scores can vary from 0 to 63 (by adding each of the 4 point scale items with corresponding 0-3 points), with scores above 20 indicative of moderate depression and scores above 29 indicative of severe depression.

Coping Scale for Adults - Short Form - General (Frydenberg \& Lewis, 1997). The Coping Scale for Adults contains self-report, five-point scales to assess coping behaviours and coping strategies. The short form (general) contains 19 items that represent each coping strategy on the long version of 73 items. The Coping Scale for Adults measures specific and general coping strategies such as seeking social support, problem solving, wishful thinking and worrying. Factor analysis has yielded four coping style profiles from the 19 item short form. These are (1) dealing with problems, (2) non-productive coping, (3) optimistic coping, and (4) sharing. The four coping styles are obtained through adding or subtracting specified items on the scale, and are then converted to an adjusted score. For example, to determine the score for 'optimism', items 4, 7, 13 and 19 are added, and the total multiplied by 5 to create the adjusted score. The higher the score for that scale, the more optimism is used as a coping strategy. 


\section{Procedure}

Permission to conduct this research was approved by the Bond University Research Ethics Committee (BUHREC). Additional approval to conduct this research was granted by the following agencies:

1) Bravehearts Inc., Queensland - a counselling service for sexually abused children, adult survivors of CSA and their non-offending families. There are currently two services located in South Brisbane and the Gold Coast, Queensland, Australia.

2) The South Australian Drug and Alcohol Services Council (DASC) - Two detoxification services and methadone programs tailored for substance abusers to receive treatment and/or therapy were accessed for this research.

In the waiting areas of these centers, potential participants were approached and offered an explanatory statement that introduced the nature of the study and topic content. The explanatory statement informed potential participants that they would be asked sensitive information relating to substance use, possible past experience of CSA and aspects of their personality. They were told that the questionnaires would take approximately 20 minutes to complete. Those who agreed to participate completed the questionnaires prior to their treatment/therapy session. To ensure anonymity of responses, participants were instructed not to provide any identifying information on any of the measures. Of the questionnaires administered, approximately 1 in 8 were returned. The low response rate was expected given the sensitive nature of the questions asked and the absence of any incentives. Questionnaires were collected over approximately 9 months.

\section{Results}

\section{Correlates of CSA in Substance Abusers}

Substance abusers who reported a history of CSA were compared with substance abusers who reported no CSA history on the measures of interest. Results indicated that, in 
comparison to substance abusers who did not disclose CSA histories, substance abusers who disclosed a history of CSA were more severely depressed, abused substances longer, and were more likely to report using drugs to alleviate negative mood states.

On the basis of their BDI-II scores, substance abusers were classified as either (1) mild to moderately or (2) severely depressed. Chi-square analysis revealed that there were proportionally more severely depressed substance abusers in the CSA substance abuser group in comparison to the no-CSA substance abuser group, $X^{2}(1)=6.69, p=.01$. Of the CSA substance abuser group, 82\% were severely depressed, whereas of the no-CSA substance abusers 49\% were severely depressed.

Contrary to predictions, multivariate analysis of covariance (MANCOVA) with age as covariate and substance abuser subgroup (CSA, no-CSA) and gender as the independent variables revealed that neither the number of times treatment was sought nor the number of times patients attempted to stop their substance use were significantly different between CSA and no-CSA substance abusers. There was no effect of gender and no interaction. The number of times CSA substance abusers reported seeking treatment for their substance problem $(M=6.37, S D=1.4)$ and the number of reported attempts to stop using $(M=5.48, S D=1.6)$ were similar to the no-CSA substance abusers $(M=5.68, S D=1.13$ and $M=6.21, S D=1.25$, respectively). However, substance abusers with a history of CSA had reportedly abused substances for longer $(M=10.99$ years, $S D=1.17)$ than substance abusers without CSA histories $(M=7.07$ years, $S D=1.21), F(2,30)=5.00, p=.013$, observed power $=.614$. Note that a number of substance abusers did not answer the corresponding questions (i.e., 15 did not state the number of times treatment was sought nor the number of years of substance abuse, and 6 did not state the number of attempts to stop using), with resultant loss of power.

MANCOVA on the four coping styles, with age as covariate and gender and substance abuser subgroup (CSA, no-CSA) as independent variables, revealed a significant multivariate 
effect of CSA status on coping style, $F(4,38)=2.88, p=.036$, observed power $=.724$. Univariate analysis showed that of the four coping styles, only optimistic coping significantly differentiated the groups. Substance abusers with a CSA history reported significantly less optimistic coping $(M=7.22, S D=2.49)$ than did substance abusers without CSA histories $(M$ $=9.39, S D=2.33), F(1,41)=9.99, p=.003$. There were no effects of gender and no interaction.

Substance abuser subgroups (CSA, no-CSA) were also compared on their selfreported motives for drug use, with motives divided into two categories: (1) use of drugs to alleviate depression or other negative mood states, and (2) use of drugs for social or recreational reasons. Chi-square tests revealed that, as expected, the CSA substance abuser group contained more individuals who reported primarily using drugs for self-medication of negative mood states (84\%) than for social/recreational reasons (16\%), whereas in the noCSA substance abuser group 45\% said they primarily used drugs to alleviate negative moods and 55\% said they primarily used drugs for social/recreational reasons, $X^{2}(1)=8.11, p=.004$.

\section{CSA Factors}

A separate group of CSA victims in CSA support groups, who did not meet the criteria for substance abuse, was examined for comparison purposes with the aim of ascertaining whether they differed from CSA substance abusers on the measures of interest. The results of these tests revealed that non-substance-abuser CSA victims did not differ from CSA substance abusers on self-reported depression or on any of the four coping styles, nor were there any differences in CSA severity, age of CSA onset or other CSA-related factors, age or gender breakdown between these groups. Given the similarity between the two CSA groups (CSA-only and CSA substance abusers), they were combined into one overall CSA group for the purpose of examining correlates of CSA-related factors such as CSA severity, type of 
perpetrator, age at CSA onset, and degree of victim confidence in having successfully dealt with the CSA trauma.

Support was obtained for the predicted relationship between CSA severity and depression. Comparison of the two CSA severity groups (severe vs. moderate) on BDI-II depression scores indicated that victims of severe CSA were more depressed $(M=29.06, S D$ $=12.05)$ than victims of moderate CSA $(M=22.00, S D=10.88)$, one-tailed $t(47)=1.90, p=$ .032. Depression scores were unrelated to type of perpetrator (familial, non-familial). There was also support for the hypothesis that a younger age of CSA onset would be associated with more severe depression. As predicted, CSAs who reported that their abuse was initiated at age 8 or younger reported more depression $(M=30.08, S D=12.16)$ than those who reported that their abuse was initiated at age 9 or older $(M=23.87, S D=11.33)$, one-tailed $t(47)=1.85, p$ $=.035$. Categorical analysis of depression level according to the criteria of the BDI-II showed that in the young age of onset group most CSA victims (88\%) were classed as severely depressed, whereas in the older age of onset group a significantly smaller majority (63\%) were classed as severely depressed, $X^{2}(1)=4.31, p=.038$.

Self-reported confidence in having successfully dealt with CSA was also related to depression severity (mild/moderate, severe) in the expected way. Of the 37 CSAs who reported that they were not confident in having dealt with their CSA, 86\% were severely depressed, whereas of the 13 CSAs who reported that they were confident in having dealt with their CSA, 46\% were severely depressed, $X^{2}(1)=8.25, p=.004$.

\section{Discussion}

In comparison to substance abusers who did not disclose CSA histories, substance abusers who disclosed a history of CSA were more severely depressed, reported less optimistic coping, and were more likely to report using drugs to alleviate negative mood states rather than for social or recreational reasons. These findings are consistent with 
previous suggestions that depression is the most common effect of CSA in both genders (Brown \& Anderson, 1991; Finkelhor, 1986), and that CSA history is associated with severe depression (Courtois, 1988; Dhaliwal et al., 1996). The present results were also in line with the notion that CSA substance abusers often use drugs or alcohol to self-medicate or block out negative emotions and memories associated with their trauma (Dhaliwal et al., 1996; Epstein et al., 1998; Evans, 1987; Miller \& Downs, 1996; Rohsenow et al., 1988). However the predicted association between CSA and substance relapse was not obtained. CSA substance abusers did not report a significantly greater frequency of attempts at substance related treatment, nor did they report a greater number of attempts to stop using substances, than did no-CSA substance abusers. However, CSA substance abusers reported a longer duration of substance abuse than did no-CSA substance abusers, even after controlling for age. This fits with the general notion that CSA history may be associated with more persistent substance use among substance abusers. Clients in treatment for substance disorders who report a CSA history may require special attention to the issue of CSA, and its sequelae such as depression, as an important component of their treatment.

Perhaps surprisingly, no differences were found in depression, coping style, CSA severity or other CSA-related factors between CSA substance abusers and CSAs who did not meet the specified criteria for substance abuse. This result suggests that on the measures employed in the present study, CSAs in treatment were remarkably similar regardless of whether they were undergoing treatment for substance abuse or CSA. Presumably, other factors than those measured in the present study are associated with the choice of some CSA victims but not others to abuse substances.

As predicted, self-reported CSA history was associated with more severe depression and less optimistic coping. Not surprisingly, confidence in having successfully dealt with CSA was associated with less severe depression in CSAs overall, although relatively few 
CSA victims expressed such confidence. Consistent with predictions, adults who were exposed to CSA at a younger age were significantly more depressed than those who reported CSA onset at an older age. These findings are consistent with Glaser and Frosh (1993) who suggested that younger age of abuse onset tends to be associated with more damaging effects. They asserted that the younger children are when exposed to CSA, the more vulnerable they are to trauma, and thus subsequently they experience more difficulties including depression. The current findings indicated that adults who were exposed to CSA prior to the age of 9 were more likely to report severe depression than those who were sexually abused at 9 or older. These results contradict Finkelhor’s (1986) suggestion that the younger child’s naiveté protects them from comprehending the severity of their trauma, and other reports that the age of the victim did not influence the extent of CSA trauma effects (Briere \& Runtz, 1985). The findings of the current study were consistent with previous research indicating that many adult survivors of CSA do not feel supported by family members, or confident that they have dealt with their abuse (Courtois, 1988). Additionally, over half of the CSA disclosing participant sample indicated that they did not report their abuse to anyone. Fearing their family's response to disclosure has been described as a common reason why some children fail to tell of their abuse (Herman, 1997).

CSA victims who reported histories of severe CSA were expected to report more substance related difficulties and depression than those who reported moderate CSA histories. Consistent with Miller and Downs (1996), the current findings indicated that adults with more severe histories of CSA (as defined by vaginal, oral or anal penetration) reported significantly more depression than adults with moderate CSA exposure (unwanted touching and fondling). The current findings are also consistent with Straus (1988), who asserted that the more intrusive forms of CSA, including attempted or completed intercourse, are associated with more negative impact than are less severe acts such as unwanted kissing and touching through 
clothes. Finkelhor (1986) suggested that penetration is the most significant predictor for the severity of CSA-related mental health impairment, and Cheasty et al. (1998) asserted that childhood penetration is associated with adult depression, as found in the present study. However, contrary to predictions, the present study failed to find an association between CSA severity and substance abuse. That is, there were not more victims of severe CSA in the CSA substance abuser group than in the CSA-only group. In addition, there were no significant differences between male and female CSA survivors on any measures in the present study, including depression and coping styles.

Attention to both CSA history and substance abuse may be crucial for successful treatment outcomes in CSA substance abusers (Hiebert-Murphy \& Woytkiw, 2000). Although there were no differences in reported relapse rates between CSA substance abusers and noCSA substance abusers, level of depression did differentiate these groups. The effectiveness of substance abuse treatment programs, and implementation of more adaptive coping styles, may be hindered by undisclosed CSA and associated depressive symptomatology. Careful screening of underlying issues pertaining to substance use may aid the adult survivor to deal more adaptively with their CSA experience and address both their childhood trauma and externalising substance disorder concurrently. The present findings suggest that the reasons offered for substance use are likely to vary between those with and those without a CSA history.

The present results do not offer any insight as to why only some CSA victims choose to abuse substances, given the apparent similarity between CSA substance abusers and nonsubstance abusing CSA victims. In future studies of this type, family background information (e.g., familial alcoholism) and/or specific diagnoses such as Post Traumatic Stress Disorder might provide further insight as such factors may interact with CSA in relation to later substance abuse. 
In summary, the present study suggests that substance abusers with a history of CSA tend to be more depressed, abuse substances longer, are more likely to self-medicate, and are less optimistic in their coping efforts than are substance abusers who do not disclose a history of CSA. The subset of substance abusers who report a history of CSA thus appears to differ from no-CSA substance abusers in clinically relevant ways that could conceivably influence their substance abuse treatment outcome. Despite the inherent difficulties involved in obtaining participants for studies of highly sensitive issues such as CSA, the results of the present study suggest that further research on CSA sequelae and the relationship between CSA and substance abuse is warranted. 


\section{References}

American Psychiatric Association. (1994). Diagnostic and Statistical Manual of Mental Disorders, $4^{\text {th }}$ ed. Washington, DC: American Psychiatric Association.

Bass, E., \& Davis, L. (1988). The courage to heal. New York: Harper \& Row.

Beck, A.T., Steer, R.A., \& Brown, G.K. (1996). Beck Depression Inventory II: Manual. New York: The Psychological Corporation.

Berry, R., \& Sellman, D. (2001). Childhood adversity in alcohol and drug dependent women presenting to outpatient. Drug and Alcohol Review, 20, 361-367.

Briere, J. (1988). The long term correlates of childhood sexual victimization. Annals New York Academy of Sciences, 528, 327-334.

Briere, J., \& Runtz, M. (1985). Symptomatology associated with prior sexual abuse in a non-clinical sample. Paper presented at the annual meeting of the American Psychological Association, Los Angeles.

Briere, J., \& Runtz, M. (1987). Postsexual abuse trauma: Data and implications for clinical practice. Journal of Interpersonal Violence, 2, 367-379.

Brown, G.R., \& Anderson, B. (1991). Psychiatric morbidity in adult inpatients with childhood histories of sexual and physical abuse. American Journal of Psychiatry, $148,55-61$.

Burnam, M.A., Stein, J.A., Golding, J.M., Siegel, J.M., Sorenson, S.B., Forsythe, A.B., \& Telles, C.A. (1988). Sexual assault and mental disorders in a community population. Journal of Consulting and Clinical Psychology, 56, 843-850.

Cappell, H., \& Greeley, J. (1987). Alcohol and tension reduction: An update on research and theory. In H.T. Blane \& K.E. Leonard (Eds.), Psychological theories of drinking and alcoholism (pp 15-54). New York: The Guilford Press.

Cheasty, M., Clare, A.W., \& Collins, C. (1998). Relation between sexual abuse in 
childhood and adult depression: Case-control study. British Medical Journal, 316, 198-201.

Chiavaroli, T. (1992). Rehabilitation from substance abuse in individuals with a history of sexual abuse. Journal of Substance Abuse Treatment, 9, 349-354.

Clay, K.M., Olsheski, J.A., \& Clay, S.W. (2000). Alcohol use disorders in female survivors of childhood sexual abuse. Alcoholism Treatment Quarterly, 18, 19-29.

Courtois, C.A. (1988). Healing the incest wound; Adult survivors in therapy. New York: W.W. Norton \& Company.

Davidson, P.O., \& Davidson, S.M. (1980). Behavioural medicine: Changing health lifestyles. New York: Brunner/Mazel Publishers.

Davis, S.K. (1997). Comprehensive interventions for affecting the parenting effectiveness of chemically dependent women. Journal of Obstetric, Gynecologic, \& Neonatal Nursing, 26, 604-610.

Dhaliwal, G.K., Gauzas, L., Antonowicz, D.H., \& Ross, R.R. (1996). Adult male survivors of childhood sexual abuse: Prevalence, sexual abuse characteristics, and long-term effects. Clinical Psychology Review, 16, 619-639.

Downs, W., Miller, B., \& Testa, M. (1991). The impact of childhood victimization experiences on women's drug use. Presented as the annual meeting for the American Society of Criminology, San Francisco, California, November 20-23.

Ellason, J.W., Ross, C.A., Sainton, K., \& Mayran, L.W. (1996). Axis I and II comorbidity and childhood trauma history in chemical dependency. Bulletin of the Menninger Clinic, 60, 39-51.

Epstein, J.N., Saunders, E., Kilpatrick, D.G., \& Resnick, H.S. (1998). PTSD as a mediator between childhood rape and alcohol use in adult women. Child Abuse and Neglect, 22, 223-234. 
Evans, S. (1987). Shame, boundaries and dissociation in chemically dependent, abusive and incestuous families. Alcoholism Treatment Quarterly, 4, 157-179.

Finkelhor, D. (1986). A sourcebook on child sexual abuse. Beverly Hills, California, USA: Sage Publications.

Frydenberg, E., \& Lewis, R. (1997). Coping Scale for Adults: Manual. Melbourne: Australian Council for Educational Research.

Glaser, D., \& Frosh, S. (1993). Child sexual abuse (2 ${ }^{\text {nd }}$ ed). Toronto: University of Toronto Press.

Goldman, R., \& Goldman, J. (1986). Australian children’s sexual experience within the family. Paper presented at the $6^{\text {th }}$ International Congress on Child Abuse and Neglect. Sydney, Australia.

Greer, B.G., \& Walls, R.T. (1997). Emotional factors involved in substance abuse in a sample of rehabilitation clients. Journal of Rehabilitation, 63, 5-9.

Hall, J.M., \& Powell, J. (2000, February). Dissociative experiences described by women survivors of childhood abuse. Journal of Interpersonal Violence, 184-204.

Harrison, P.A., Hoffman, N.G., \& Edwall, G.E. (1989). Differential drug use patterns among sexually abused adolescent girls in treatment for chemical dependency. International Journal of Addictions, 24, 499-514.

Heffernan, K., Cloitre, M., Tardiff, K., Marzuk, P.M., Portera, L., \& Leon, A.C. (2000). Childhood trauma as a correlate of lifetime opiate use in psychiatric patients. Addictive Behaviours, 25, 797-803.

Herman, J.L. (1997). Trauma and recovery. New York: BasicBooks.

Hiebert-Murphy, D., \& Woytkiw, L. (2000). A model for working with young women dealing with child sexual abuse and addictions. Journal of Substance Abuse Treatment, 18, 387-394. 
Hien, D., \& Scheier, J. (1996). Trauma and short-term outcome for women in detoxification. Journal of Substance Abuse Treatment, 13, 227-231.

Hopper, J. (1996-2003). Child Abuse: Statistics, Research, and Resources. Available at: http://www.jimhopper.com.

Hunter, J.A. (1991). A comparison of the psychosocial maladjustments of adult males and females sexually molested as children. Journal of Interpersonal Violence, 6, 205217.

Ireland, T., \& Widom, C.S. (1994). Childhood victimization and risk for alcohol and drug arrests. International Journal of Addictions, 29, 235-274.

Jarvis, T.J., Copeland, J., \& Walton, L. (1998). Exploring the nature of the relationship between child sexual abuse and substance use among women. Addiction, 93, 865-875.

Jellinek, E.M. (1952). The phases of alcohol addiction. Quarterly Journal of Studies on Alcohol, 13, 673-684.

Kalichman, S.C., Benotsch, E., Rompa, D., \& Gore-Felton, C. (2001).

Unwanted sexual experiences and sexual risks in gay and bisexual men: Associations among revictimization, substance use, and psychiatric symptoms. Journal of Sex Research, 38, 1-9.

Kalichman, S.C., Williams, E., Cherry, C., Belcher, L., \& Nachimson, D. (1998). Sexual coercion, domestic violence, and negotiating condom use among low-income African-American women. Journal of Women's Health, 7, 371-378.

Kellogg, N.D., Burge, S., \& Taylor, E.R. (2000). Wanted and unwanted sexual experiences and family dysfunction during adolescence. Journal of Family Violence, 15, 55-68.

Kendler, K.S., Bulik, C.M., Silberg, J., Hettema, J.M. (2000). Childhood sexual abuse 
and adult psychiatric and substance use disorders in women: An epidemiological and Cotwin control analysis. Archives of General Psychiatry, 57, 953-961.

Kolodner, G., \& Frances, R. (1993). Recognizing dissociative disorders in patients with chemical dependency. Hospital and Community Psychiatry, 44, 1041-1043.

Kovach, J. (1986). Incest as a treatment issue for alcoholic women. Alcoholism Treatment Quarterly, 3, 1-15.

Krug, R.S. (1989). Adult male report of childhood sexual abuse by mothers: Case descriptions, motivations and long-term consequences. Child Abuse and Neglect, 13, 111-119.

Langeland, W. \& Hartgers, C. (1998). Child sexual and physical abuse and alcoholism: A review. Journal of Studies on Alcohol, 59, 336-348.

Lindberg, F.H., \& Distad, L.J. (1985). Survival responses to incest: Adolescents in crisis. Child Abuse and Neglect, 9, 521-526.

Lisak, D. (1994). The psychological impact of sexual abuse: Content analysis of interviews with male survivors. Journal of Traumatic Stress, 7, 525-548.

Longabaugh, R., Mattson, M.E., Connors, G.J. \& Cooney, N.L. (1994). Quality of life as an outcome variable in alcoholism treatment research. Journal of Studies on Alcohol, 12, 119-124.

Marcenko, M.O., Kemp, S.P., \& Larson, N.C. (2000, July). Childhood experiences of abuse, later substance use, and parenting outcomes among low-income mothers. American Journal of Orthopsychiatry, 316-326.

Marlatt, G.A., \& Gordon, J.R. (1985). Relapse prevention: Maintenance strategies in the treatment of addictive behaviors. New York: Guilford Press.

Miller, B.A., \& Downs, W.R. (1996). Violent victimization among women with alcohol problems. Recent Developments in Alcoholism, 12, 81-101. 
Miller, B.A., Downs, W.R., Gondoli, D.M., \& Keil, A. (1987). The role of childhood sexual abuse in the development of alcoholism in women. Violence and Victims, 3, 157-172.

Monroe, A.D., Levy, S., \& McQuade, W. (1997). Effects of gender on documentation of alcohol use in patients with psychiatric symptoms. Substance Abuse, 18, 79-87.

Mullen, P.E., Martin, J.L., Anderson, J.C., Romans, S.E., \& Herbison, G.P. (1996).

The long-term impact of the physical, emotional, and sexual abuse of children: A community study. Child Abuse and Neglect, 20, 7-21.

Neumann, D.A., Houskamp, B.M., Pollock, V.E., \& Briere, J. (1996). The long-term sequelae of childhood sexual abuse in women: A meta-analytic review. Child Maltreatment, 1, 6-22.

Pearce, E.J., \& Lovejoy, F.H. (1995). Detecting a history of childhood sexual experiences among women substance abusers. Journal of Substance Abuse Treatment, 12, 283-287.

Rice, C., Mohr, C.D., Del Boca, F.K., Mattson, M.E., Young, L., Brady, K., \& Nickless, C. (2001). Self-reports of physical, sexual and emotional abuse in an alcoholism treatment sample. Journal of Studies on Alcohol, 62, 114-130.

Roesler, T.A., \& Dafler, C.E. (1993). Chemical dissociation in adults sexually victimized as children: Alcohol and drug use in adult survivors. Journal of Substance Abuse Treatment, 19, 537-543.

Rohsenow, D.J., Corbett, R., \& Devine, D. (1988). Molested as children: A hidden contribution to substance abuse? Journal of Substance Abuse Treatment, 5, 13-18.

Schaefer, M.R., Sobieraj, K., \& Hollyfield, R.L. (1988). Prevalence of childhood physical abuse in adult male veteran alcoholics. Child Abuse \& Neglect, 12, 141-149.

Scher, D., \& Twaite, J.A. (1999). The relationship between child sexual abuse and 
alexithymic symptoms in a population of recovering adult substance abusers. Journal of Child Sexual Abuse, 8, 25-40.

Scott, K.D. (1992). Childhood sexual abuse: Impact on a community’s mental health status. Child Abuse and Neglect, 16, 285-295.

Silverman, A.B., Reinherz, H.Z., \& Giaconia, R.M. (1996). The long-term sequelae of child and adolescent abuse: A longitudinal community study. Child Abuse and Neglect, 20, 709-723.

Singer, M.I., Petchers, M.K., \& Hussey, D. (1989). The relationship between sexual abuse and substance abuse among psychiatrically hospitalised adolescents. Child Abuse and Neglect, 13, 319-325.

Spak, L., Spak, F., \& Allebeck, P. (1998). Sexual abuse and alcoholism in a female population. Addiction, 93, 1365-1373.

Spataro, J., Moss, S.A., \& Wells, D.L. (2001). Child sexual abuse: A reality for both sexes. Australian Psychologist, 36, 177-183.

SPSS. (2003). Statistical Package Version 12.0.1 for Windows (Computer software). Chicago, IL: SPSS Inc.

Straus, M.B. (1988). Abuse and victimization across the life span. Baltimore, USA: The Johns Hopkins University Press.

Swift, W., Copeland, J., \& Hall, W. (1996). Characteristics of women with alcohol and other drug problems: Findings of an Australian national survey. Addiction, 91, 1141-1150.

Thomson, J. (2001). Private violence: A public affair - Policing domestic violence and sexual assault in Victoria. Melbourne, Australia: Women’s Legal Resource Centre.

Unger, J.B., Kipke, M.D., Simon, T.R., Montgomery, S.B., \& Johnson, C.J. (1997). 
Homeless youths and young adults in Los Angeles: Prevalence of mental health problems and the relationship between mental health and substance abuse disorders. American Journal of Community Psychology, 25, 371-382.

Van Hasselt, V.B. \& Hersen, M. (2000). Aggression and violence: An introductory text. Boston: Allyn and Bacon.

Widom, C.S., Ireland, T., \& Glenn, P.J. (1995). Alcohol abuse in abused and neglected children followed up: Are they at increased risk? Journal of Studies on Alcohol, 56, 207-217.

Wilsnack, S.C., Vogeltanz, N.D., Klassen, A.D. \& Harris, T.R. (1997). Childhood sexual abuse and women's substance abuse: National survey findings. Journal of Studies on Alcohol, 58, 264-271.

Young, E.B. (1990). The role of incest issues in relapse. Journal of Psychoactive Drugs, 22, 249-258. 